\title{
Impact of greenhouse gas stabilization initiatives on the Croatian petroleum industry
}

\author{
L. Maurovic \\ University of Zagreb, \\ Faculty of Mining, Geology and Petroleum Engineering, \\ Department of Petroleum Engineering, Croatia
}

\begin{abstract}
Even though the impact of greenhouse gas (GHG) emissions on global climate began at the end of $19^{\text {th }}$ century it took more than half a century for scientists to start addressing this problem. Since the impact was global, variable and long term, for a long time there was no initiative of countries or emission intensive industries to control and accept responsibility for GHG emissions. Today the greatest part of the responsibility for adverse environmental impact due to GHG emissions lies with industry and the energy sector. The petroleum industry is one of the GHG emission intensive industries. Beside direct $\mathrm{CO}_{2}$ and $\mathrm{CH}_{4}$ emissions with oil and gas production, the petroleum industry is also characterized with high-energy intensity and final products with high emission potentials. Besides facing the same problems as other petroleum industries due to new high ecological standards, the Croatian petroleum industry is also faced with a lack of domestic legal regulative addressing stabilization of GHG emissions and, at the same time, increasing international directives for adoption of international environmental regulations. Croatia has signed and ratified several international agreements considering GHG emission stabilization. The UNFCCC was ratified in 1996 and in 1999 Croatia signed the Kyoto Protocol by which it has committed to reduce GHG emissions by 5\% from 1990 levels. Since the admission to the EU is one of main political and economical goals of Croatia the ratification of the Kyoto Protocol in Croatia is not questionable. Due to the wide implementation of GHG emissions limitation laws there is a necessity to incorporate climate change factors into corporative strategies of petroleum companies in order to reduce corporate risks and to assure long-term competitive advantages.
\end{abstract}

Keywords: climate change, greenhouse emission, Croatian petroleum industry. 


\section{Introduction}

With the beginning of the industrial revolution at the end of $19^{\text {th }}$ century and growth of consumption of all kinds of fuels the negative environmental impact of humankind rapidly started to increase. Even though the impact of greenhouse gases on global climate system has begun during the end of the $19^{\text {th }}$ century the scientific addressing of this problem didn't begin until second half of $20^{\text {th }}$ century. Since the impact was global, variable and long-term for a long time nor countries nor companies took any initiative to control and to accept the responsibility for greenhouse gases emission.

Nowadays the highest share of the responsibility for negative environmental impact, as on local so on regional and global scale, is upon industry and energy sector. Environmental impacts of energy sector, if analyzing from the energy producers to final energy consumers, are various. Most certainly, presently the most important and the most analyzed energy sector environmental impact is the problem of greenhouse gases emission with consequential air pollution, especially in urban areas, acid rain problem, high ozone concentrations and most of all, global $\mathrm{CO}_{2}$ problem. Rest of the impacts is usually local and therefore could be solved, prevented or put to acceptable levels with improvement of technical and technological performances. The emissions from energy sector are mostly due to fossil fuel combustion and they include carbon dioxide $\left(\mathrm{CO}_{2}\right)$, carbon monoxide $(\mathrm{CO})$, sulphur dioxide $\left(\mathrm{SO}_{2}\right)$, nitro oxides $(\mathrm{NOx})$ and solid compounds like soot. Beside their negative impact on health of living creatures, $\mathrm{SO}_{2}$ and $\mathrm{NOx}$ are also known as "acid" gases because the products of some chemical reaction of $\mathrm{SO}_{2}$ and $\mathrm{NOx}$ are characterised with high $\mathrm{pH}$ values. These products are sedimented from atmosphere as wet (acid rains) and dry deposits. Beside that, nitro oxides with some volatile organic compounds (VOC) are part of ozone $\left(\mathrm{O}_{3}\right)$ forming processes by whose concentrations the greenhouse effect is even more intensified. The greenhouse gas mostly responsible for the mentioned greenhouse effect is carbon dioxide which concentrations have increased by $30 \%$ from the beginning of the $19^{\text {th }}$ century and currently amounts over 370 parts per million (ppm). Getting out to the atmosphere, mostly by fossil fuel combustion, carbon dioxide is present there for almost 120 years. Due to present predictions, if there are no appropriate steps towards stabilization and decrease of global $\mathrm{CO}_{2}$ emissions, worlds $\mathrm{CO}_{2}$ concentrations will, in next 50 years, climb up to warning and disturbing level of $550 \mathrm{ppm}$ [1].

With the development of global ecological consciousness during the 1970s of the $20^{\text {th }}$ century, after the recognition of global warming problem and global climate change as its consequence, worlds leading economies started to take more resolute steps towards decrease of greenhouse gases. In 1988 the United Nations Organization formed the International Panel on Climate Change. After that, in 1992, followed the Rio Earth Summit, the international summit in Rio de Janeiro, that represented first public acknowledgment of the need for greenhouse gases emissions reduction and climate change mitigation. The result of the summit was the United Nations Framework Convention on Climate Change. The United Nations Framework Convention on Climate Change (UNFCCC), ratified 
by over 180 nations, came into force in 1994 with long-term goal to achieve "stabilization of greenhouse gas concentrations in the atmosphere at a level that would prevent dangerous anthropogenic interference with the climate system" [2]. The first step towards achieving this goal was set of national emission reduction targets prescribed by the Kyoto Protocol. Kyoto Protocol came into force on February $16^{\text {th }} 2005$ and became a legal obligation for 128 world countries, which have signed and ratified it. Due to reduction of global costs of achievement of proposed emission reductions there were three flexible mechanisms presented by Kyoto Protocol respectively Joint Implementation (JI), Clean Development Mechanisms (CDM) and Emission Trade (ET) [3].

\section{Greenhouse gases emissions in Croatia}

In 1996 the Republic of Croatia ratified and became fully responsible member of UNFCCC. By ratifying UNFCCC Croatia committed itself to systematic recording of greenhouse gases emissions of which the IPCC is informed in annual greenhouse gas emissions report, and has also accepted the obligation to keep its greenhouse gases emission under 1990s levels. Beside UNFCCC, measuring and recording of greenhouse gases emissions in Croatia is also obligatory due to national Air Protection Law, which came into force in 1990. Beside UNFCCC Croatia has also signed several other, for national energetics important, international settlements. One of them is the Convention on Long Range Transboundary Air Pollution (LRTAP) of the United Nations Economic Commission for Europe (UNECE), which resulted with several protocols. That is how Croatia accepted the Protocol on Further Reduction of Sulphur emissions, according to which Croatia has to reduce its sulphur emissions by $22 \%$ until 2010 in relation to 1980 s levels. That means that the levels of $\mathrm{SO}_{2}$ emissions should be kept under 117 kilotonnes. In 1999 under LRTAP Convention came out also The Protocol to abate acidification, eutrophication and ground - level ozone (MPME Protocol), which Croatia still didn't ratified. By MPEM Protocol, beside $\mathrm{SO}_{2}$, the limitations of $\mathrm{NOx}$, Non-methane volatile organic compounds (NMVOC) and amonium (NH3) are also set. By its ratification, which will probably be one of the conditions when joining the European Union, Croatia will be obligated to keep its NOx emissions on 1990s levels, to reduce its $\mathrm{SO}_{2}$ emissions by $61 \%$, NMVOC by $14 \%$ and its $\mathrm{NH}_{3}$ emissions by $19 \%$ until 2010 compared to the same emissions at 1990s levels.

Croatia also signed and ratified Wienna Convention on ozone layer protection, Montreal Protocol on ozone polluting compounds, Heavy metal Protocol and Protocol on organic polluters.

In March of 1999 Croatia has signed the Kyoto Protocol by which it is committed to reduce its greenhouse gases emission by 5\% in period from 2008 to 2012 compared to base year 1990. By choosing 1990 for a base year Croatian Ministry of Foreign Affairs has chosen a bad term for Croatia since the emissions were extremely low in 1990 first of all due to the war in the country, but also because of electricity import and high share of renewable sources (hydropower) in domestic electricity production which is one of the most 
emission intensive sectors. There is also a problem with energy capacities, which were in possession of the Republic of Croatia in 1999 but were situated on territory of other republics of former Yugoslavia. These capacities were taken into consideration when setting the 1990's emission levels for Croatia. Today they are no longer in Croatian possession. Croatia still didn't ratify the Kyoto Protocol, but since joining to European Union is one of the main goals of Croatia, its ratification is not questionable. Croatia appealed to the UNFCCC for higher emission quotas in the base year. The negotiations are still running [4]. The $\mathrm{CO}_{2}$-eq emissions from energy industries in Croatia are shown in figure $1[5]$.

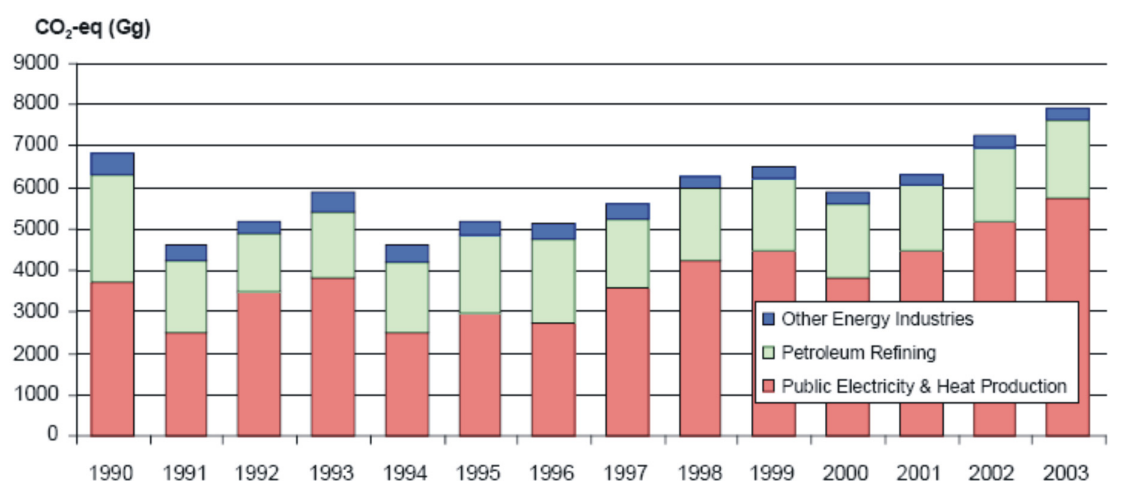

Figure 1: The $\mathrm{CO}_{2}$-eq emissions from energy industries in Croatia.

Calculations of $\mathrm{SO}_{2}$ and NOx emissions in Croatia are done by EMEP/ CORINAIR methodology, while calculation of $\mathrm{CO}_{2}$ emissions is carried out by using IPCC methodology. The combustion emissions have the highest share in overall $\mathrm{CO}_{2}, \mathrm{SO}_{2}$ and $\mathrm{NOx}$ emissions in Croatia (figure 2) [6]. The $\mathrm{SO}_{2}$ emissions are mainly due to fuel combustion in industrial energy plant and thermal power plants. The decreased levels of $\mathrm{SO}_{2}$ emissions in last five years are result of emission reductions in power sector due to more favourable structure and better quality of used fuels. The NOx emission is largely the result of fuel combustion in road transport, and depends on type and age of vehicles and technological solution for emission reduction. In 2004 there was a decrease in total $\mathrm{CO}_{2}$ emissions mainly because favourable hydrometerological conditions and consequently more intensive hydro power plants performance and reduced generation form thermal power plants, but the emissions were still $1 \%$ above the commitment defined by the Kyoto Protocol. In addition it is expected that the energy demand in Croatia will rise in next few years so the Kyoto Protocol target will be easily exceeded. The expected difficulties in meeting the Kyoto Protocol targets are, as already mentioned, caused by very low $\mathrm{CO}_{2}$ emissions of the base year, so Croatia will have to make additional actions in form of subsidies, regulations, laws and environmental policy in general to meet the obligated greenhouse gases emissions targets [6]. 


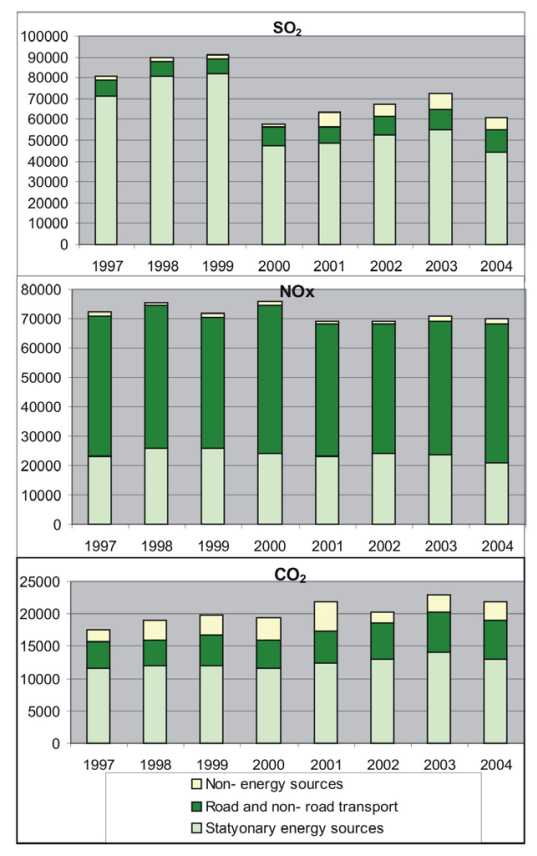

Figure 2: Emission trends in Croatia - $\mathrm{SO}_{2}, \mathrm{NOx}$ and $\mathrm{CO}_{2}$.

\section{Croatian petroleum industry and greenhouse gases emissions}

Reviewing presently used resources for energy production it is obvious that fossil fuels still have the highest share. Oil, natural gas and coal represent around $90 \%$ of commercial energy used worldwide. According to current predictions, considering today's rate of energy consumption and technical and technological development, fossil fuel reserves are expected to last for at least one more century.

Petroleum industry is highly emission intensive. Not only that there is a direct carbon dioxide $\left(\mathrm{CO}_{2}\right)$ and methane $\left(\mathrm{CH}_{4}\right)$ emissions during oil and natural gas production, but petroleum industry is also characterized with high-energy intensity and with final products of high emission potentials. The fugitive emissions of methane from oil and gas activities in Croatia are shown in figure 2 [5]. Fossil fuels are still dominant sources of energy supply, so to meet the energy demand petroleum industry today is called upon not just to provide an effective management of oil and gas reserves, but also to manage to do that in safe and efficient manner with as low as practically possible ecological footprint.

Since petroleum industry, regarding its business activities, which are considered to be environmentally intensive, takes up special public attention great emphasis has been put on quality of environmental management system based on effective management with systematic approaches and adequate 
mechanisms, which have to ensure compliance with present, as national as the global, environmental policies and regulations. Principles of environmental protection were initiated and became embedded in petroleum business for more than half of a century, but it is only few decades ago that environmental protection started to be seen as an integral part of sustainable development approach. Task of petroleum company's environmental management system is not only to provide improvement, necessary to cope with new environmental standards, technological development and to meet public expectations, but also to control and supervise that policy statements, guidelines, programs and field procedures are properly conducted. Environmental management techniques have successfully integrated into all segments of upstream operational procedures and activities, from exploration work, through drilling operations, field development, production of oil or natural gas and ending by abandonment. With effective environmental management system it is ensured that during all of these activities preventive environmental and safety measures are taken even before starting operations. Some consider the high environmental standards and regulations and its implementation to be the main principle that underpins petroleum industry's business and decision - making process.

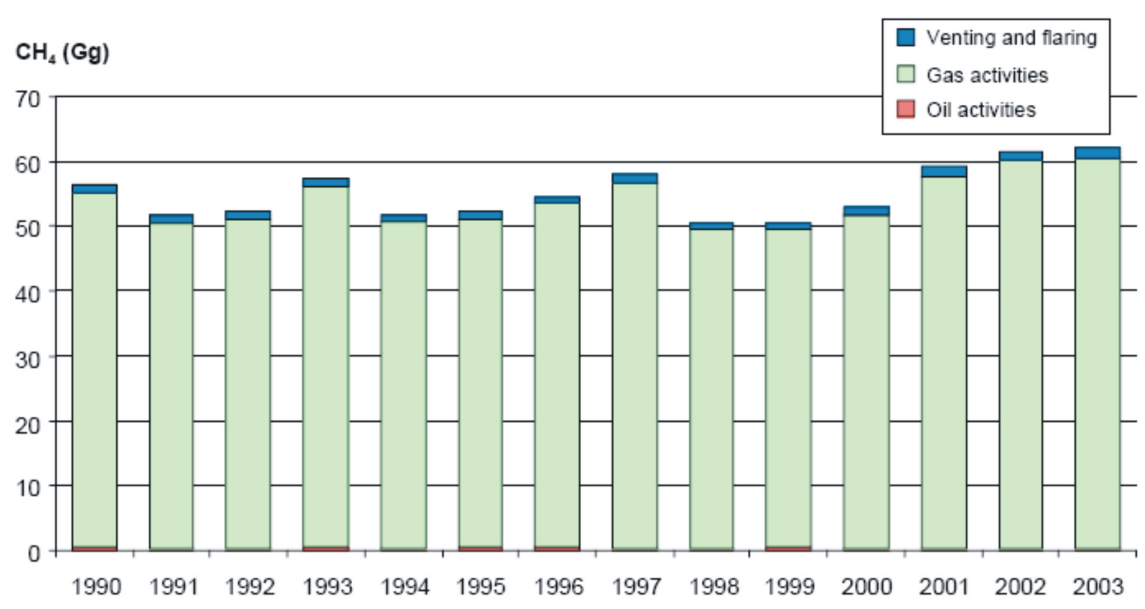

Figure 3: The fugitive emissions of methane from oil and gas activities.

When talking about environmental protection in petroleum business there are several issues that should be addressed such as biodiversity, climate change, oil spill prevention, waste and water management. To support the needs of ever increasing world development, energy demand will, in next few decades, still strongly depend on oil and gas resources. Consequently, in order to fulfil the worldwide increasing demands, petroleum companies have to develop and adopt new technologies to increase recovery and to spread their upstream activities to unexploited areas. 
The biggest player in Croatian petroleum industry is INA. INA is mediumsized, vertically integrated petroleum company specialized in oil and natural gas exploration and production, refining and marketing of petroleum products. It owns all of the country's oil and natural gas reserves and refining capacities and it is also responsible for natural gas imports to Croatia. The rest of the petroleum business activities are conducted by independent companies operating under umbrella of INA Group. INA's subsidiaries are engaged in LPG business, natural gas transportation and providing integrated oilfield services. Until 2000, when it was partially privatized, INA was fully state owned company. At the moment, MOL, the Hungarian petroleum company, as INA's strategic partner, owns $25 \%$ +1 share of INA's equities. The rest is in possession of the Croatian government.

INA operates on 43 onshore oil fields, 11 onshore gas fields, 2 offshore gas fields (Adriatic sea), and owns and operates two fuels refineries located in Rijeka and Sisak. Considering greenhouse gases emissions INA is one of the companies that will be affected with the implementation of greenhouse gases stabilization regulations. Among INA's capacities the biggest emitters are gas-condensate field Molve and Rijeka and Sisak refinery. The fugitive emissions of ozone precursors and $\mathrm{SO}_{2}$ from oil refining in Croatia are shown in table 1 [5].

Table 1: The fugitive emissions of ozone precursors and $\mathrm{SO}_{2}$ from oil refining in Croatia.

\begin{tabular}{|c|c|c|c|c|c|c|}
\cline { 2 - 7 } \multicolumn{1}{c|}{} & \multicolumn{7}{c|}{ Emissions (Gg) } \\
\cline { 2 - 7 } \multicolumn{1}{c|}{} & 1990 & 1995 & 2000 & 2001 & 2002 & 2003 \\
\hline $\mathrm{CO}$ & 0.62 & 0.49 & 0.47 & 0.44 & 0.44 & 0.44 \\
\hline $\mathrm{NOx}$ & 0.41 & 0.33 & 0.32 & 0.29 & 0.30 & 0.29 \\
\hline $\mathrm{NMVOC}$ & 4.25 & 3.37 & 3.26 & 3.04 & 3.05 & 3.02 \\
\hline $\mathrm{SO}_{2}$ & 6.38 & 5.06 & 4.90 & 4.57 & 4.58 & 4.53 \\
\hline
\end{tabular}

The Rijeka refinery is medium sized refinery located on the Adriatic coast with access to deep-sea port and JANAF pipeline system. The refinery typically runs 3-3.5 million tonnes per year of crude oil, producing a range of petroleum products for the domestic and export markets.

The Sisak refinery is located $50 \mathrm{~km}$ from Zagreb, the capital of Croatia and also the biggest consumption area in Croatia. The refinery runs 2-2.2 million tonnes per year of crude oil produced by INA plus Russian crude oil imported via connections to Druzba 1 and Druzba 2 pipelines.

The gas-condensate field Molve is situated in north-western part of Croatia in most onshore gas productive part of Croatia. It has extremely unfavourable reservoir conditions with pressures up to 1100 bar (16 100 PSI), temperatures up to $235^{\circ} \mathrm{C}, 25 \% \mathrm{CO}_{2}, 3 \% \mathrm{SO}_{2}$ and significant values of mercury in produced natural gas and condensate [7]. Yearly emissions on gas- condensate field Molve are shown in table 2.

Croatian petroleum industry will be affected by greenhouse gases emission stabilization in country on several levels. Since, even with additional measures, 
Croatia won't be able to fulfil its obligations towards Kyoto Protocol, and since it is not likely that EU Commission will approve increase in emission quotas for the base year, Croatia will have to find the solution for its problem of greenhouse gases emissions in Kyoto Protocol flexible mechanisms. Considering present economy status, and since it is one of the Annex I parties, it is most likely that in few years Croatia will take part in Joined Implementation projects as a host country. Through these projects Croatia will gain needed foreign capital, efficient technologies and finally, decrease in greenhouse gases emissions.

Table 2: $\quad$ Emissions on gas-condensate field Molve.

\begin{tabular}{|c|c|c|c|c|c|c|}
\cline { 2 - 7 } \multicolumn{1}{c|}{} & \multicolumn{7}{c|}{ Emissions $\left(10^{6} \mathrm{~g}\right)$} \\
\cline { 2 - 7 } \multicolumn{1}{c|}{} & 1990 & 1995 & 2000 & 2001 & 2002 & 2003 \\
\hline $\mathrm{CO}_{2}$ & 233.6793 & 391.5306 & 310.0001 & 348.6376 & 350.6254 & 353.2544 \\
\hline $\mathrm{H}_{2} \mathrm{~S}$ & 0,149 & 0.103 & 0.058 & 0.065 & 0.028 & 0.007065 \\
\hline
\end{tabular}

Croatia's participation in EU Trading System will probably pose costs of $€ 60$ million per year. This will also mean that the EU emission trading directives should be interpolated into domestic laws and that Croatia will have to develop national laws for national emission trading system regulation. That is expensive and long-term process that has partially started with the energy and environmental law reforms, but finalization of this process is not in sight in the near future. Another problem that rises up is the development of effective and qualitative monitoring system for continuous monitoring of stationary and mobile emission sources. Only few of Croatian companies have installed systems for continuous emission monitoring according to EU standards, which development and installation will bring additional financial investments to the companies.

The development of national emission trading system in Croatia is questionable for several reasons. One of the reasons is emission allowances allocation that will be done by the government under National Allocation Plan. Making of National Allocation Plan is one of the most important and one of the most controversial as political as economical issues. By making it the government will be directly affecting companies business and their market competitiveness. By gaining a small number of emission allowances the company is forced to make additional investments to achieve bigger emission reductions in order to keep its emissions within obligated levels. Another problem with the development of national emission trading system in Croatia is the fact that many of the potential emission allowance sellers will have to achieve significant emission reductions (in order to create tradable quotas) before the actual emission allowance buyers even exist, That will lead to less number of market transactions than expected. And finally, there is also a question whether the domestic companies are financially strong enough to enter international emission markets.

Croatian petroleum industry is taking steps today to limit greenhouse gas emissions from their own operations through the development and implementation of cleaner and energy efficient technologies. INA's activities to 
reduce its climate change impact include investment in cogeneration facilities, research and development of renewable and environment friendly refinery products, reduction and, where possible, elimination of venting and flaring and capture and sequestration of $\mathrm{CO}_{2}$. INA is also putting a lot of effort to motivate their customers to reduce their own emissions through increasing energy efficiency and use of environment friendly products through several marketing projects. There is also the necessity for INA to start to incorporate climate change factors into its corporative strategy in order to minor corporate risks and to assure long-term competitive advantages.

\section{Conclusion}

Today the greatest part of the responsibility for adverse environmental impact due to GHG emissions, as on local so on regional and global scale, lies on industry and energy sector. Petroleum industry is one of GHG emission intensive industries. Beside direct $\mathrm{CO}_{2}$ and $\mathrm{CH}_{4}$ emissions with oil and gas production, petroleum industry is also characterized with high-energy intensity and final products with high emission potentials.

In March of 1999 Croatia has signed the Kyoto Protocol by which it is committed to reduce its greenhouse gases emission by $5 \%$ in period from 2008 to 2012 compared to base year 1990. By choosing 1990 for a base year Croatian Foreign Ministry has chosen a bad term for Croatia since the emissions were extremely low in 1990. Croatia still didn't ratify the Kyoto Protocol, but since joining to European Union is one of the main goals of Croatia, its ratification is not questionable. It is expected that energy demand in Croatia will rise in next few years so the Kyoto Protocol target will be easily exceeded.

Besides facing the same problems as other petroleum industries due to new high ecological standards, Croatian petroleum industry is also faced with lack of domestic legal regulative addressing stabilization of GHG emissions and, at the same time, increasing international directives for adoption of international environmental regulations. Only few of Croatian companies have installed systems for continuous emission monitoring according to EU standards, which development and installation will bring additional financial investments to the petroleum company. There is also the necessity for INA to start to incorporate climate change factors into its corporative strategy in order to minor corporate risks and to assure long-term competitive advantages.

\section{References}

[1] http://cdiac.esd.orln.gov

[2] United Nations Framework Convention on Climate Change, http://unfecc.int

[3] The Kyoto Protocol, http://unfccc.int

[4] www.mzopu.hr 
670 Management of Natural Resources, Sustainable Development and Ecological Hazards

[5] ENRG- Energy Research and Environmental Protection Institute, Croatia's National Inventory Report for the period 1990 - 2003, Zagreb, 2005

[6] Republic of Croatia, Ministry of Economy, Labour and Entrepreneurship, Energy in Croatia 2004, Annual Energy Report, Zagreb, 2006.

[7] www.ina.hr

[8] Energy Institute "Hrvoje Pozar", Energy Sector Development Strategy, NN (38/02), Zagreb, 2002. 